\title{
Somatostatin and its receptors from fish to mammals
}

\author{
Manuel D. Gahete, Jose Cordoba-Chacón, Mario Duran-Prado, María M. Malagón, \\ Antonio J. Martinez-Fuentes, Francisco Gracia-Navarro, Raul M. Luque, and Justo P. Castaño \\ Department of Cell Biology, Physiology and Immunology, University of Córdoba, Instituto Maimónides de Investigación \\ Biomédica de Córdoba (IMIBIC), and CIBER Fisiopatología de la Obesidad y la Nutrición (CIBERobn 06/03), Córdoba, Spain \\ Address for correspondence: Dr. Justo P. Castaño, Dpt. de Biologia Celular, Fisiologia e Inmunologia, Edif. Severo Ochoa. \\ Planta 3, Campus Univ. de Rabanales, Universidad de Cordoba, 14014-Cordoba, Spain. justo@uco.es.
}

Somatostatin (SST) and its receptors (sst) make up a molecular family with unique functional complexity and versatility. Widespread distribution and frequent coexpression of sst subtypes underlies the multiplicity of (patho)physiological processes controlled by SST (central nervous system functions, endocrine and exocrine secretion, cell proliferation). This complexity is clearly reflected in the intricate evolutionary development of this molecular family. Recent studies postulate the existence of an ancestral somatostatin/urotensin II (SST/UII) gene, which originated two ancestral, SST and UII, genes by local duplication. Subsequently, segment duplication would have originated two diverging SST genes in both fish (SS1/SS2) and tetrapods [(SST/cortistatin(CST))]. SST/CST actions are mediated by a family of GPCRs (sst1-5) encoded by five different genes. sst1-4 sequences are highly conserved compared with sst5, suggesting unique evolutionary and functional relevance for the latter. Indeed, we recently identified novel truncated but functional sst5 variants in several species, which may help to explain part of the complexity of the SST/CST/sst family. Comparative and phylogenetic analysis of this molecular family would enhance our understanding of its paradigmatic evolutionary complexity and functional versatility.

Keywords: somatostatin; cortistatin; somatostatin receptors; evolution; vertebrates

\section{Introduction}

Somatostatin-14 (SST14) is the best-known member of a family of related peptides, which were likely originated during the process of tetraploidization that took place during vertebrate evolution. Indeed, genomes sequencing analyses suggest that two rounds of extensive gene duplications occurred in early vertebrate evolution, which resulted from two more or less complete genome doublings ( $2 \mathrm{R}$ hypothesis). In addition, all euteleosts share a common ancestor that underwent a third tetraploidization (3R). Nevertheless, this hypothesis does not explain all vertebrate gene duplications, suggesting that processes of local duplications have also occurred in vertebrate lineage. ${ }^{1}$ Many families of neuroendocrine peptides, including that of the SST genes, have been expanded during this evolutive process, ${ }^{1}$ and as result, the SST family is composed of several related peptides highly conserved during evolution of vertebrate lineage. ${ }^{2}$

Peptides that constitute this family exert their functions through binding and activation of five distinct seven trans-membrane domain (TMD) Gprotein coupled receptors (GPCRs), the so-called somatostatin receptors (sst1-5). Components of the sst family are encoded by five different genes that also underwent the process of local/segmented duplication occurred in early vertebrates, ${ }^{3}$ however, the sequence of sst subtypes has been highly conserved during vertebrate evolution. Although each sst subtype seems to preferentially mediate one or more specific SST actions, most tissues co-express several sst subtypes, suggesting that the precise actions of SST depend on the interaction of the ssts expressed in each cell. ${ }^{4,5}$

Since the discovery of SST in 1973 as an inhibitor factor of GH-release, ${ }^{6}$ a vast amount of 
patho-physiological functions have been associated to this peptides family. ${ }^{4}$ By and large, SST acts as a universal inhibitor of endocrine and exocrine secretions. Thus, SST inhibits GH secretion in all vertebrate species studied, ${ }^{7-18}$ while its actions in other pituitary secretions vary in a species-dependent manner. ${ }^{19-30}$ In addition, SST14 inhibits exocrine secretions s $^{4,31}$ and modulates nervous system functions and digestive and immune system actions. ${ }^{32,33}$ In contrast, other non-SST14 SST family peptides, such as CST, have been reported to exert different, and even opposite actions in a tissue- or speciesdependent manner, probably by binding to sst subtypes with different affinities than SST-14 or by activating disparate intracellular pathways. ${ }^{34-36}$

In sum, the SST/ssts system represents a paradigm of a very complex, versatile, and functionally relevant neuroendocrine system, which has been highly conserved since its appearance, probably, in early vertebrate evolution.

\section{Evolution of the SST gene}

SST was originally discovered as a 14-residue peptide (SST14), with a disulfide bridge that allows its cyclic structure. ${ }^{6}$ However, transcription of SST gene leads in fact to the synthesis of a pre-prohormone (PPSS1), which can codify various SSTrelated peptides. The most important one besides SST14 is an amino-terminally extended form of 28 residues, called SST28, which was isolated from the porcine gut and exhibits a distinct tissular distribution. Indeed, whereas SST14 is predominantly produced in the central nervous system (CNS) but also in many peripheral organs, SST28 is mainly synthesized by mucosal epithelial cells along the gastrointestinal tract (GIT).

As mentioned earlier, the processes of local and segmented duplication that occurred in the first stages of vertebrate evolution originated a large number of SST-related peptides encoded by up to four different genes. ${ }^{1}$ Because SST14 is present in all vertebrate phyla, ${ }^{37-40}$ except for holocephalan fish, ${ }^{41}$ and its nucleotide-amino acidic sequence has been highly conserved across species, its coding gene, SS1, is considered the ancestral SST gene. ${ }^{2}$ However, comparative genome organization studies suggest that SS1 gene shares with urotensin (UII) gene a common ancestor present in early vertebrates. Although both peptides show limited structural sim- ilarities and the nucleotide sequences of their precursors are not highly conserved, both SST and UII peptides exhibit a disulfide bridge, and a share common FWK motif, which is essential for their biological activity. Based on these evidences, Tostivint et al. have postulated the existence of an ancestral SST/UII gene, which underwent two rounds of gene duplication (2R), and thereby produced two SSTand two UII-related genes along the evolutionary process. ${ }^{2}$

In accordance with the $2 \mathrm{R}$ hypothesis, the tetraploidization that occurred in early vertebrates originated the mentioned SS1 gene and a new SSTrelated gene, termed somatostatin 2 (SS2) in lower vertebrates and cortistatin (CST) in mammals. In contrast with the high conservation of SST14 sequence along vertebrate lineage, SS2 and CST peptides show variable structure (despite sharing a unique proline residue at position 2), and this may explain that the relation between fish SS2 and human CST has remained unclear during years. Recently, genomic organization analyses have clarified it revealing that SS2 and CST derive from orthologous genes. SS2/CST peptidic precursor has lower similarities with that of SS1, but the C-terminal regions of both are highly conserved and, similar to that occurred in SS1, various peptides of diverse length are generated from the SS2 propeptide (CST14, CST17, CST28, CST29, SS2-22, SS225). Indeed, in human, CST17 and SST14 share 11 amino acids, including the FWK motif, which makes up the receptor binding core, as well as the two cysteine residues responsible for their conserved cyclic structure. ${ }^{20}$ This sequence identity and structural homology between SST and CST could explain their close pharmacology. ${ }^{42}$ Indeed, both peptides exhibit a comparable subnanomolar binding affinity to the sst subtypes. On the other hand, CST, unlike SST, has been reported to bind to the receptor for ghrelin (GHS-R) ${ }^{43}$ and also to the Mrgx2 receptor, ${ }^{44}$ although this latter receptor seems to be somewhat promiscuous and more specific for proadrenomedullin and its related peptides.

In fish lineage, two more SST-related genes have been described in literature. SS3, previously known as SSII, was initially found in anglerfish, trout, and goldfish. Most peptides derived from PSS3 have 2528 -aminoacids in length, with amino acids changes at $\left[\mathrm{Tyr}^{7}, \mathrm{Gly}^{10}\right]$ SST14. The vicinity between SS3 and SS1 loci suggest that the two genes arose by a local 
duplication, and thus they are considered orthologous genes. In addition, in catfish and zebrafish, a SS4 gene, also named SSIII or atypical SSII, has been reported that encoded for SST variants containing Tyr, Ser, Arg, and Ala residues at positions 6, 10, 11 , and 13. Although its origin is still unknown, it seems to be a paralogous gene that could have resulted from the $3 \mathrm{R}$ event that occurred in the early ray-finned fish lineage. ${ }^{2}$

\section{Evolution of sst genes}

As mentioned earlier, diversity of ssts, together with intrincated evolution of SST-related peptides, seems to be responsible for the multiplicity and complexity of SST actions. Nowadays, ssts are classified as Class A GPCRs and are encoded by five intronless genes, sst1-5, that give rise to six different receptor isoforms, including a carboxyterminal spliced variant of the sst $2 .{ }^{4,31}$ Although ssts have been described in all vertebrate classes studied to date, no data have been reported in invertebrates metazoans. According to their sequence identity and pharmacological properties, ssts can be subdivided into two groups, namely SRIF1, which includes sst2, sst3, and sst5, and SRIF2, which includes sst1 and sst4. Phylogenetic analysis of ssts suggests that, as other GPCRs, a putative sst precursor gene was duplicated and originated SRIF1 and SRIF2 receptors genes early in the vertebrate evolution, before tetrapods and teleosts split up. According with the $2 \mathrm{R}$ hypothesis, a second step consisted in an additional duplication event that derived into sst 1 , sst4, sst3, and an ancestral sst2/sst5. At last, the ancestral sst $2 /$ sst 5 divided into the actual sst 2 and $s s t 5 .{ }^{3}$ In fish, the scenario of sst subtypes is more complex due to polyploidization occurred during fish lineage evolution, which resulted in several and different copies of the same gene. Thus, some teleosts have two sst1 (A and $B$ ), two sst3 (A and B), and three sst5 (A, B, and C). In spite of this branched evolutive process, sst sequences are highly conserved between species, and within the sst subtype family, being mostly divergent at both, $\mathrm{N}$ - and $\mathrm{C}$-terminal domains. Interestingly, the most conserved subtype between species is the sst1, whereas the most divergent is the sst5. For example, sst1A and B from Carassius auratus shows $76 \%$ similarity with their human counterpart. Moreover, within each species, sst 5 seems to be also the most divergent subtype. Thus, human sst1 shows $64 \%, 62 \%$, and $58 \%$ similarity with sst 2 , sst3, and sst 4 , respectively, whereas human sst5 shows $42 \%, 48 \%, 47 \%$, and $46 \%$ with sst 1 , sst 2 , sst 3 , and sst 4 , respectively. ${ }^{31}$ This lower similarity for the sst5 subtype suggest a unique evolutionary relevance for this receptor, which is supported by its involvement in certain atypical processes. ${ }^{45}$ In line with this, and despite the difficulty to identify additional ssts in mammals, we have discovered several truncated variants of the human, ${ }^{46}$ rat, mouse, ${ }^{47}$ and pig sst5 subtype, which increase the complexity of the SST/ssts system.

\section{SST functions from fish to mammals}

\section{Control of endocrine secretions}

SST family peptides are one of the major negative regulatory systems of endocrine secretions in vertebrates, both by acting directly on endocrine tissues (pituitary, pancreas, liver, adrenal gland) or indirectly through regulatory centers (mainly hypothalamus). ${ }^{4}$

\section{Pituitary}

Actions on somatotropes. SST is the foremost negative regulator of $\mathrm{GH}$ secretion and its inhibitory function is conserved during vertebrate evolution. In teleost, although SST14 is a potent inhibitor of basal and stimulated GH secretion in several species, ${ }^{20}$ the function of other SST peptides is less clear. In goldfish, mammalian SST14 and SST28 were equipotent in inhibiting GH release from the pituitary, whereas salmonid SS3-25 and catfish SS222 had no effect on GH release. ${ }^{32}$ In addition, it has been reported that goldfish SS2-28 was a more potent inhibitor of GH than SST14. ${ }^{32}$ In other nonmammalian vertebrate phyla, SST action on GH release is slightly different to that exerted in teleost. In amphibians and reptilians, SS1 by itself has no apparent effect on $\mathrm{GH}$ release, but inhibits the in vitro release of $\mathrm{GH}$ stimulated by TRH (the main $\mathrm{GH}$ release stimulatory factor in amphibian and reptilian pituitary glands), ${ }^{9,10}$ whereas both SS1 and SS2 are able to inhibit GHRH-induced rise of GH in frog. ${ }^{10}$ In chicken, SST inhibits basal and GHRHstimulated GH secretion. ${ }^{14,16}$ In mammals, SST is essential to establish and maintain pulsatility of $\mathrm{GH}$ secretion; however, several studies have revealed that the precise role of SST, and also GHRH, in the control of GH secretion is species- and, even, 
gender-dependent, suggesting a complex relationship between these two peptides and additional factors. ${ }^{48}$ Specifically, in human, SST and CST had an inhibitory effect on GH release both in vivo and in vitro, probably through activation of sst 2 and sst5. ${ }^{5,28}$ Taken together, these data indicate that, although the role of SST axis in regulation of GH secretion is well conserved in the vertebrate lineage, the precise peptides and receptors involved in this control are phyla- and species-dependent.

Actions on other pituitary cell types. SST has been also shown to inhibit most of pituitary secretions. Specifically, it inhibits prolactin (PRL) release in vivo and in vitro from fish pituitary cells ${ }^{29}$ and, in earlier studies, from rat. ${ }^{19}$ In human, in vitro experiments showed that sst2 is the main receptor involved in the inhibition of PRL secretion from fetal human pituitary cells, although, in most prolactinomas and somato-prolactinomas, SST and CST have been found to exert a suppressive effect on PRL secretion, mainly acting through sst 5 subtype. ${ }^{28}$ Surprisingly, SST seems to exert a stimulatory role in ACTH secretion in teleost, ${ }^{49}$ whereas it has long been known to negatively regulate ACTH secretion in vitro in mammals. ${ }^{25}$ Specifically, several studies indicate that sst 2 and sst 5 mediate the inhibitory response of corticotropes to SST. ${ }^{23}$ In addition, it has been reported that SST and CST display a similar, strong inhibitory effect on ACTH hypersecretion in patients with Cushing's disease. ${ }^{21}$ On the other hand, SST has rarely been found to modulate normal gonadotrope function. Thus, an isolated study on male rat anterior pituitary cells in culture showed that SST did not affect basal release of either LH or FSH, whereas it suppressed LHRH-induced release of $\mathrm{LH}$, but not that of FSH. ${ }^{30}$ Conversely, several studies have demonstrated that SST inhibits gonadotropin release from human pituitary adenomas (both clinically nonfunctioning adenomas and somatotrope adenomas cosecreting the alphasubunit). ${ }^{24}$ More recently, use of receptor-specific somatostatin analogs on clinically nonfunctioning pituitary adenoma cells cultured in vitro indicated that the regulation of alpha-subunit secretion by SST is mediated through the subtypes sst2A, sst3, and sst5. ${ }^{50}$ SST has also been reported to inhibit stimulated TSH release in vitro from fetal human pituitary cells, as well as in cultures of pituitary cells from rats, birds, and amphibians. ${ }^{27,29,51,52}$ In fact, in this latter species, it has been demonstrated that both SS1 and SS2 inhibited TSH release induced by PACAP-38 but did not alter spontaneous (basal) TSH secretion, suggesting a similar role for both neurohormones in the regulation of thyrotrope function in vitro. ${ }^{27}$ When viewed together, the data obtained in normal and tumoral pituitary cells in culture from mammalian and nonmammalian vertebrates suggest that the pleiotropic regulatory/modulatory capability of SST axis on pituitary cell function is clearly dependent on the specific species, peptide, and receptor subtype considered and could have evolutionary implications.

\section{Extrapituitary actions}

Vertebrate pancreatic islets express all five sst subtypes, being sst1, 2, and 5 those predominantly expressed in human islets. Immunohistochemical colocalization of sst $1-5$ with insulin, glucagon, and SST has revealed that, in humans, $\beta$-cells are rich in sst 1 and sst5, $\alpha$-cells in sst2, and $\delta$-cells in sst5, suggesting a receptor-dependent regulation of pancreatic secretions. In teleost, injection of SS225 , but not SST14, reduced plasma insulin levels; whereas, injections of both equally depressed plasma glucagon levels, ${ }^{53}$ demonstrating that SST isoforms may possess disparate physiological effects. In rats, pioneer studies showed selective suppression of glucagon by SST14 and of insulin by SST28. In human, SST and CST displays the same in vivo inhibitory effects on insulin secretion in either physiological and pathological conditions (e.g., acromegaly or prolactinoma).${ }^{54}$ Current knowledge suggest that, multiple ssts would act in concert to convey the inhibitory signal of SST axis on insulin and glucagon release, through an action that is species-dependent, and where it is critical the specific combination and the levels of expression of the ssts involved. ${ }^{55-61}$ Specifically, sst2 seems to be the main receptor mediating the inhibitory actions of SST in insulin and glucagon in humans, with sst1 and sst5 playing also a role in regulating insulin. In contrast, in rodents, sst 5 appear as the predominant receptor mediating SST-induced inhibition of insulin release and sst2 seems to mediate glucagon inhibition. ${ }^{61}$

SST has also been shown to be able to regulate endocrine secretions in other peripheral organs such as ovary, thyroid, and adrenal gland. Specifically, in teleosts, SST plasma level are inversely correlated 
with thyroid hormone levels and SST inhibits TSH-stimulated release of T4, and T3 as well as that of calcitonin from murine parafollicular cells. ${ }^{4}$ Furthermore, recent studies using human medullary thyroid carcinoma TT-cell line have shown that activation of specific ssts by its selective ligands regulates diverse cellular processes, including proliferation, calcitonin secretion, and RNA synthesis, in a mechanism involving sst2, sst5, and sst $1 .{ }^{62}$ In the ovary, SST acts as regulator of progesterone release, specifically by inhibiting basal, but not LHstimulated, progesterone release from cultured human granulosa-luteal cells. ${ }^{63}$ Finally, adrenal gland is a known target of SST action, which displays a rich concentration of sst 2 and modest levels of sst 1 and 3 . Recently, SST has been shown to regulate also secretion of catecholamines from chromaffin cells. In this case, SST does not inhibit but enhances the release of catecholamines induced by a high concentration of acetylcholine in bovine adrenal medullary cells. ${ }^{64}$

\section{Digestive actions}

In gastrointestinal tract (GIT), SST is mainly secreted from stomach D cells into the extracellular space to act as a paracrine factor on nearby endocrine cells and as an autocrine factor to inhibit its own secretion; however, it is also present in the myenteric and submucosal nerve plexus of the gut, where it functions as a neurotransmitter and neuromodulator. These and other widespread sources of SST production in GIT make it to contain approximately $65 \%$ of the entire SST content in the body. In addition, although the results are quite variable depending on the technique used, variable expression of all ssts has been described in vertebrate stomachs and GIT. ${ }^{5}$

In mammals, SST is known to inhibit release of GIT peptides, including secretin, ghrelin, CCK, vasoactive intestinal polypeptide (VIP), gastric inhibitory peptide (GIP), motilin, enteroglucagon, gastric acid, peptide intrinsic factor, bile, and colonic fluids. ${ }^{4}$ Not only GIT secretions are affected by SST, but other GIT functions such as bowel motility, gastric emptying, GIT transit time, small bowel segmentation, gallbladder contractility, bowel flow, splanchnic and liver blood flow, and intestinal absorption of carbohydrates, amino acids, calcium, and triacylglycerols are inhibited as well. ${ }^{4}$ Although the above actions are mediated by the SST-14/sst2 tandem in mammals, other actions such as inhibi- tion of peptide YY and glucagon-like peptide secretion from intestinal endocrine cells seem to be mediated by sst 5 and SST- $28 .{ }^{4}$

Although SST actions are well characterized in mammalian GIT, studies in nonmammalian vertebrates are scarce. Specifically, in amphibians, SST seems to inhibit pepsinogen secretion and, in teleost, the only digestive action reported for SS1-14 is reduction of basal and/or stimulated gastric acid secretion. $^{32}$

Taken together, these results indicate that although GIT functions of SST are mainly mediated by SST-14 through sst2, more studies in nonmammalian vertebrates are needed to establish the precise role of SST axis in GIT functions of vertebrate lineage.

\section{Neuronal actions}

Comparative analyses developed in several vertebrate species indicate that SST and sst2A are widely distributed in the brain of vertebrates, although the other sst subtypes are also expressed in certain CNS regions, suggesting that the general organization of the somatostatinergic system has been well conserved during evolution. ${ }^{33,65}$ Indeed, SST is able to act as a neurotransmitter, a neuropeptide, or a neuromodulatory agent in the CNS, mediating motor, cognitive, and sensory effects, acting mainly through sst $2 \mathrm{~A}$ and other subtypes coexpressed in different brain regions. ${ }^{33}$ Acting as a neurotransmitter, SST inhibits presynaptically glutamate release in various mammalian, bird, and amphibian models by acting through sst 1 , sst 2 , or sst 5 , depending on the anatomical structure, ${ }^{33}$ and also inhibits GABA release in cat and rat. ${ }^{33}$ In mammals, intracerebroventricular administration of SST increases locomotor activity through activation of sst 2 and sst4, whereas its depletion has been reported to induce learning and memory deficits. These actions in central and peripheral nervous system seems to be mediated by sst $2 .{ }^{33}$ Interestingly, SST and CST, which is highly expressed in CNS, share several functional properties, such as the depression of neuronal activity. ${ }^{66}$ However, in nervous system, both peptides exert clearly distinct actions. Indeed, it has been found that CST at low doses decreased locomotor activity, an effect opposite to that observed for SST at the same doses. However, at a high doses SST and CST induce seizures and barrel rotation, suggesting that CST may act through ssts under 
saturating conditions. In addition, SST increases REM without affecting slow-wave sleep, while CST induces slow-wave sleep, ${ }^{66}$ again suggesting a different role of SST family components in the control of relevant physiological processes.

\section{Immune system actions}

Accumulated evidence suggests that the immune and neuroendocrine systems cross-talk by sharing ligands and receptors. Certainly, hormones and neuropeptides produced by the neuroendocrine system often modulate the function of lymphoid organs and immune cells. Immunohistochemical analysis has revealed that SST is expressed in the thymus and other lymphoid organs of amphibians, birds, and mammals (mouse, rat, pig, and humans). ${ }^{67}$ In addition, presence of CST, sst1, sst2, and sst3, as well as, MrgX2 has been reported in normal human thymus, ${ }^{67}$ suggesting an autocrine or paracrine regulation in this organ. Interestingly, immune cells (T-cell, B-cell, monocytes, macrophages, dentritic cells, etc.) express CST and GHS-R but not SST, and the presence of different ssts seems to be speciesdependent in these cell types; for example, sst2 and sst 4 are predominantly expressed in rodents, whereas sst 2 and sst 3 are mainly expressed in human immune cell subsets. ${ }^{67}$ Moreover, immune cells can alter their sst subtype expression panel during maturation/differentiation. Taken together, these data suggest that, at least in mammals, CST could mediate the autocrine or paracrine effect of SST axis in immune cells through activation of ssts, MrgX2, and/or GHS-R.

In mammals, SST has been reported to act in an inhibitory fashion on T-cell, B-cell, and monocyte-macrophage lineages. However, a biphasic response has been often observed, that is, inhibition of a certain response at low SST concentrations and stimulation of that same response at higher concentrations. Specifically, SST inhibits the proliferation of mouse and human T-lymphocyte through binding sst 2 or possibly sst $3 .{ }^{67}$ In addition, SST acting through sst 2 and/or sst5 inhibit the production of immunoglobulins by murine B cells, diminishes the number of rat antigen-specific plasmatic cells formed during a primary immune response, and reduces the in vitro differentiation of human peripheral blood B-lymphocytes into plasmatic cells. ${ }^{67}$ However, the data concerning SST action on monocyte-macrophage lineage are con- tradictory. Indeed, SST has been reported to exert inhibitory and stimulatory effects on the chemotaxis of macrophages, and on the cytokine release and the effector functions of macrophages and monocytes. ${ }^{67}$ However, because CST expression levels correlate with immune cell differentiation and activation, ${ }^{68,69}$ and $\mathrm{MrgX} 2$ and GHS-R are widely expressed in the immune system, CST, rather than SST, has been proposed to be a major endogenous regulatory factor in the immune system. ${ }^{36}$ Indeed, CST has been claimed as a therapeutic antiinflammatory peptide on arthritis and lethal endotoxemia treatment. ${ }^{35,36}$

Hence, similar to that occurred in SST digestive actions, more studies are needed in nonmammalian vertebrates to understand the immune role of SST axis in this lineage.

\section{New ssts receptors}

In addition to the remarkable versatility of the SST/sst family, new players have emerged in the SST physiology during recent years. Although sst are typically known as 7TMD receptors encoded by intronless genes, and only one splice variant of sst2 has been described in mammals, ${ }^{4,31}$ our group has recently identified various truncated sst 5 variants that possess less than 7TMD and are generated by cryptic introns in $3^{\prime}$-region of the gene. ${ }^{46}$ Generation of splice variants with less than the canonical 7TMDs is a relatively common process in GPCR families, which seems to provide an additional step in the regulation of pathways controlled by these receptors. These truncated sst 5 receptors have been identified in human ${ }^{46}$ as well as in pig, rat, and mouse. ${ }^{47}$ The fact that sst5 sequence is the less intraspecifically conserved among sst subtypes and that it is involved in certain atypical processes ${ }^{45}$ together with the notion that it possess a recent common antecessor with sst2, led us to think as plausible to find new variants of sst 5 gene.

Specifically, the complete CDS of human truncated sst5 variants comprise 822 and $651 \mathrm{nu}-$ cleotides, which encode proteins of 273 and 216 amino acids, respectively. Analysis of their corresponding secondary structures (hydrophobicity profiles) indicated that these sequences would encode truncated sst 5 variants with five and four putative TMDs, and thus the receptor variants were termed sst5TMD5 and sst5TMD4. Both receptors 
are functional in terms of mobilization of intracellular calcium, being these actions selective for SST14 and CST17, respectively. Truncated sst5 isoforms are expressed differentially in normal tissues and are also present in diverse types of pituitary tumors, where they are mostly coexpressed with native ssts, mainly sst 2 and sst5. Studies are underway aimed at elucidating the precise pathophysiological relevance of the novel sst 5 variants.

\section{Concluding remarks}

Available evidence suggests that the intrinsic evolutive process that took place during vertebrate lineage diversification underlies the wide structural and functional variety and complexity observed in the SST/ssts family. Indeed, SST-related peptides comprise a family of two genes that coded for, at least, four peptides in tetrapods and up to four genes in some teleost groups. In addition, these peptides exert their biological actions through binding to, at least, eight identified receptors, including the carboxyterminal spliced variant sst2B and the two truncated isoforms, sst5TMD5 and sst5TMD4, encoded by five independent genes. Consequently, the evolutive expansion process that experienced the ancestral SST and sst genes during the early history of vertebrate lineage imparted the SST/sst family a high complexity and versatility in controlling a wide range of relevant biological processes.

\section{Acknowledgments}

This work was supported by Research Grants BFU2007-60180/BFI and BFU2008-01136/BFI (Ministerio de Ciencia e Innovación), BIO-139 and CTS-1705 (Junta de Andalucía), Ayudas predoctorales de formación en investigación en salud del Fondo de Investigación Sanitaria (FIS, ISCIII: FI06/00804; to JCC), Programa Nacional de becas de FPU (FPU-AP20052473, to MDG) and Programa Ramón y Cajal del Ministerio de Educación y Ciencia (RYC-2007-00186, to R.M.L.), Spain, and IPSEN Pharmaceuticals (to J.P.C). CIBER is an initiative of Instituto de Salud Carlos III, Ministerio de Ciencia e Innovación, Spain.

\section{Conflicts of interest}

The authors declare no conflict of interest.

\section{References}

1. Larhammar, D., G. Sundstrom, S. Dreborg, et al. 2009. Major genomic events and their consequences for vertebrate evolution and endocrinology. Ann. N.Y. Acad. Sci. 1163: 201-208.

2. Tostivint, H., L. Joly, I. Lihrmann, et al. 2006. Comparative genomics provides evidence for close evolutionary relationships between the urotensin II and somatostatin gene families. Proc. Natl. Acad. Sci. USA 103: 2237-2242.

3. Moaeen-ud-Din, M. \& L.G. Yang. 2009. Evolutionary history of the somatostatin and somatostatin receptors. J. Genet. 88: 41-53.

4. Patel, Y.C. 1999. Somatostatin and its receptor family. Front. Neuroendocrinol. 20: 157-198.

5. Moller, L.N., C.E. Stidsen, B. Hartmann \& J.J. Holst. 2003. Somatostatin receptors. Biochim. Biophys. Acta. 1616: $1-84$.

6. Brazeau, P., W. Vale, R. Burgus, et al. 1973. Hypothalamic polypeptide that inhibits the secretion of immunoreactive pituitary growth hormone. Science 179: 77-79.

7. Gahete, M.D., M. Duran-Prado, R.M. Luque, et al. 2009. Understanding the multifactorial control of growth hormone release by somatotropes: lessons from comparative endocrinology. Ann. N.Y. Acad. Sci. 1163: 137-153.

8. Cook, A.F. \& R.E. Peter. 1984. The effects of somatostatin on serum growth hormone levels in the goldfish, Carassius auratus. Gen. Comp. Endocrinol. 54: 109-113.

9. Hall, T.R. \& A. Chadwick. 1984. Effects of synthetic mammalian thyrotrophin releasing hormone, somatostatin and dopamine on the secretion of prolactin and growth hormone from amphibian and reptilian pituitary glands incubated in vitro. J. Endocrinol. 102: 175-180.

10. Jeandel, L., A. Okuno, T. Kobayashi, et al. 1998. Effects of the two somatostatin variants somatostatin-14 and [Pro2, Met13] somatostatin-14 on receptor binding, adenylyl cyclase activity and growth hormone release from the frog pituitary. J. Neuroendocrinol. 10: 187192.

11. Le Bail, P.Y., J.P. Sumpter, J.F. Carragher, et al. 1991. Development and validation of a highly sensitive radioimmunoassay for chinook salmon (Oncorhynchus tshawytscha) growth hormone. Gen. Comp. Endocrinol. 83: 75-85.

12. Melamed, P., N. Eliahu, B. Levavi-Sivan, et al. 1995. Hypothalamic and thyroidal regulation of growth hormone in tilapia. Gen. Comp. Endocrinol. 97: 13-30.

13. Peng, C. \& R.E. Peter. 1997. Neuroendocrine regulation of growth hormone secretion and growth in fish. Zool. Stud. 36: 79-89. 
14. Piper, M.M. \& T.E. Porter. 1997. Responsiveness of chicken embryonic somatotropes to somatostatin (SRIF) and IGF-I. J. Endocrinol. 154: 303-310.

15. Sheridan, M.A. \& J.D. Kittilson. 2004. The role of somatostatins in the regulation of metabolism in fish. Comp. Biochem. Physiol. B Biochem. Mol. Biol. 138: 323330.

16. Spencer, G.S., S. Harvey, A.R. Audsley, et al. 1986. The effect of immunization against somatostatin on growth rates and growth hormone secretion in the chicken. Comp. Biochem. Physiol. A. 85: 553-556.

17. Tannenbaum, G.S., J.C. Painson, A.M. Lengyel \& P. Brazeau. 1989. Paradoxical enhancement of pituitary growth hormone $(\mathrm{GH})$ responsiveness to $\mathrm{GH}$-releasing factor in the face of high somatostatin tone. Endocrinology 124: 1380-1388.

18. Very, N.M., D. Knutson, J.D. Kittilson \& M.A. Sheridan. 2001. Somatostatin inhibits growth of rainbow trout. J. Fish Biol. 59: 157-165.

19. Enjalbert, A., J. Epelbaum, S. Arancibia, et al. 1982. Reciprocal interactions of somatostatin with thyrotropinreleasing hormone and vasoactive intestinal peptide on prolactin and growth hormone secretion in vitro. Endocrinology 111: 42-47.

20. Gahete, M.D., M. Duran-Prado, R.M. Luque, et al. 2008. Are somatostatin and cortistatin two siblings in regulating endocrine secretions? in vitro work ahead. Mol. Cell Endocrinol. 286: 128-134.

21. Giordano, R., A. Picu, L. Bonelli, et al. 2007. The activation of somatostatinergic receptors by either somatostatin-14 or cortistatin-17 often inhibits ACTH hypersecretion in patients with Cushing's disease. Eur. J. Endocrinol. 157: 393-398.

22. Grau, E.G., C.A. Ford, L.M. Helms, et al. 1987. Somatostatin and altered medium osmotic pressure elicit rapid changes in prolactin release from the rostral pars distalis of the tilapia, Oreochromis mossambicus, in vitro. Gen. Comp. Endocrinol. 65: 12-18.

23. Hofland, L.J., J. Van Der Hoek, R. Feelders, et al. 2005. The multi-ligand somatostatin analogue SOM230 inhibits ACTH secretion by cultured human corticotroph adenomas via somatostatin receptor type 5. Eur. J. Endocrinol. 152: 645-654.

24. Klibanski, A., J.M. Alexander, H.A. Bikkal, et al. 1991. Somatostatin regulation of glycoprotein hormone and free subunit secretion in clinically nonfunctioning and somatotroph adenomas in vitro. J. Clin. Endocrinol. Metab. 73: 1248-1255.

25. Luque, R.M., M.D. Gahete, U. Hochgeschwender \& R.D. Kineman. 2006. Evidence that endogenous SST inhibits
ACTH and ghrelin expression by independent pathways. Am. J. Physiol. Endocrinol. Metab. 291: 395-403.

26. Luque, R.M., M.D. Gahete, R.J. Valentine \& R.D. Kineman. 2006. Examination of the direct effects of metabolic factors on somatotrope function in a non-human primate model, Papio anubis. J. Mol. Endocrinol. 37: 25-38.

27. Okada, R., K. Yamamoto, Y. Ito, et al. 2006. Effects of pituitary adenylate cyclase-activating polypeptide, vasoactive intestinal polypeptide, and somatostatin on the release of thyrotropin from the bullfrog pituitary. Ann. N.Y. Acad. Sci. 1070: 474-480.

28. Rubinfeld, H., M. Hadani, G. Barkai, et al. 2006. Cortistatin inhibits growth hormone release from human fetal and adenoma pituitary cells and prolactin secretion from cultured prolactinomas. J. Clin. Endocrinol. Metab. 91: 2257-2263.

29. Shimon, I., J.E. Taylor, J.Z. Dong, et al. 1997. Somatostatin receptor subtype specificity in human fetal pituitary cultures. Differential role of SSTR2 and SSTR5 for growth hormone, thyroid-stimulating hormone, and prolactin regulation. J. Clin. Invest. 99: 789-798.

30. Yu, W.H., M. Kimura \& S.M. McCann. 1997. Effect of somatostatin on the release of gonadotropins in male rats. Proc. Soc. Exp. Biol. Med. 214: 83-86.

31. Olias, G., C. Viollet, H. Kusserow, et al. 2004. Regulation and function of somatostatin receptors. J. Neurochem. 89: 1057-1091.

32. Klein, S.E. \& M.A. Sheridan. 2008. Somatostatin signaling and the regulation of growth and metabolism in fish. Mol. Cell Endocrinol. 286: 148-154.

33. Viollet, C., G. Lepousez, C. Loudes, et al. 2008. Somatostatinergic systems in brain: networks and functions. Mol. Cell Endocrinol. 286: 75-87.

34. de Lecea, L., J.R. Criado, O. Prospero-Garcia, et al. 1996. A cortical neuropeptide with neuronal depressant and sleep-modulating properties. Nature 381: 242-245.

35. Gonzalez-Rey, E., A. Chorny, R.G. Del Moral, et al. 2007. Therapeutic effect of cortistatin on experimental arthritis by downregulating inflammatory and Th1 responses. Ann. Rheum. Dis. 66: 582-588.

36. Gonzalez-Rey, E., A. Chorny, G. Robledo \& M. Delgado. 2006. Cortistatin, a new antiinflammatory peptide with therapeutic effect on lethal endotoxemia. J. Exp. Med. 203: 563-571.

37. Tostivint, H., I. Lihrmann, C. Bucharles, et al. 1996. Occurrence of two somatostatin variants in the frog brain: characterization of the cDNAs, distribution of the mRNAs, and receptor-binding affinities of the peptides. Proc. Natl. Acad. Sci. USA 93: 12605-12610. 
38. Tostivint, H., D. Vieau, N. Chartrel, et al. 2002. Expression and processing of the $[\operatorname{Pro}(2), \operatorname{Met}(13)$ ]somatostatin-14 precursor in the intermediate lobe of the frog pituitary. Endocrinology 143: 3472-3481.

39. Trabucchi, M., H. Tostivint, I. Lihrmann, et al. 2002. Polygenic expression of somatostatin in the sturgeon Acipenser transmontanus: molecular cloning and distribution of the mRNAs encoding two somatostatin precursors. J. Comp. Neurol. 443: 332-345.

40. Vaudry, H., N. Chartrel \& J.M. Conlon. 1992. Isolation of [Pro2,Met13] somatostatin-14 and somatostatin14 from the frog brain reveals the existence of a somatostatin gene family in a tetrapod. Biochem. Biophys. Res. Commun. 188: 477-482.

41. Conlon, J.M. 1990. [Ser5]-somatostatin-14: isolation from the pancreas of a holocephalan fish, the Pacific ratfish (Hydrolagus colliei). Gen. Comp. Endocrinol. 80: 314-320.

42. de Lecea, L. \& J.P. Castano. 2006. Cortistatin: not just another somatostatin analog. Nat. Clin. Pract. Endocrinol. Metab. 2: 356-357.

43. Deghenghi, R., M. Papotti, E. Ghigo \& G. Muccioli. 2001. Cortistatin, but not somatostatin, binds to growth hormone secretagogue (GHS) receptors of human pituitary gland. J. Endocrinol. Invest. 24: 1-3.

44. Robas, N., E. Mead \& M. Fidock. 2003. MrgX2 is a high potency cortistatin receptor expressed in dorsal root ganglion. J. Biol. Chem. 278: 44400-44404.

45. Luque, R.M., M. Duran-Prado, S. Garcia-Navarro, et al. 2006. Identification of the somatostatin receptor subtypes (sst) mediating the divergent, stimulatory/inhibitory actions of somatostatin on growth hormone secretion. Endocrinology 147: 2902-2908.

46. Duran-Prado, M., M.D. Gahete, A.J. Martinez-Fuentes, et al. 2009. Identification and characterization of two novel truncated but functional isoforms of the somatostatin receptor subtype 5 differentially present in pituitary tumors. J. Clin. Endocrinol. Metab. 94: 26342643.

47. Córdoba-Chacón, J., M.D. Gahete, M. Duran-Prado, et al. 2009. Identification and characterization of new functional truncated variants of somatostatin receptor subtype 5 in rodents. Cell Mol. Life Sci. 67: 1147-1163.

48. Goldenberg, N. \& A. Barkan. 2007. Factors regulating growth hormone secretion in humans. Endocrinol. Metab. Clin. North Am. 36: 37-55.

49. Langhorne, P. 1986. Somatostatin stimulates ACTH release in brown trout (Salmo trutta L.). Gen. Comp. Endocrinol. 61: 71-75.

50. Pawlikowski, M., H. Lawnicka, H. Pisarek, et al. 2007.
Effects of somatostatin-14 and the receptor-specific somatostatin analogs on chromogranin $\mathrm{A}$ and alphasubunit (alpha-SU) release from "clinically nonfunctioning" pituitary adenoma cells incubated in vitro. $J$. Physiol. Pharmacol. 58: 179-188.

51. Geris, K.L., B. De Groef, E.R. Kuhn \& V.M. Darras. 2003. In vitro study of corticotropin-releasing hormoneinduced thyrotropin release: ontogeny and inhibition by somatostatin. Gen. Comp. Endocrinol. 132: 272-277.

52. Dieguez, C., S.M. Foord, J.R. Peters, et al. 1984. Interactions among epinephrine, thyrotropin (TSH)-releasing hormone, dopamine, and somatostatin in the control of TSH secretion in vitro. Endocrinology 114: 957-961.

53. Eilertson, C.D. \& M.A. Sheridan. 1993. Differential effects of somatostatin-14 and somatostatin-25 on carbohydrate and lipid metabolism in rainbow trout Oncorhynchus mykiss. Gen. Comp. Endocrinol. 92: 62-70.

54. Grottoli, S., V. Gasco, F. Broglio, et al. 2006. Cortistatin17 and somatostatin-14 display the same effects on growth hormone, prolactin, and insulin secretion in patients with acromegaly or prolactinoma. J. Clin. Endocrinol. Metab. 91: 1595-1599.

55. Singh, V., M.D. Brendel, S. Zacharias, et al. 2007. Characterization of somatostatin receptor subtype-specific regulation of insulin and glucagon secretion: an in vitro study on isolated human pancreatic islets. J. Clin. Endocrinol. Metab. 92: 673-680.

56. Efendic, S., R. Luft \& V. Grill. 1974. Effect of somatostatin on glucose induced insulin release in isolated perfused rat pancreas and isolated rat pancreatic islets. FEBS Lett. 42: 169-172.

57. Gerich, J.E., R. Lovinger \& G.M. Grodsky. 1975. Inhibition by somatostatin of glucagon and insulin release from the perfused rat pancreas in response to arginine, isoproterenol and theophylline: evidence for a preferential effect on glucagon secretion. Endocrinology 96: 749-754.

58. Brown, M., J. Rivier \& W. Vale. 1976. Biological activity of somatostatin and somatostatin analogs on inhibition of arginine-induced insulin and glucagon release in the rat. Endocrinology 98: 336-343.

59. Strowski, M.Z., M.P. Dashkevicz, R.M. Parmar, et al. 2002. Somatostatin receptor subtypes 2 and 5 inhibit corticotropin-releasing hormone-stimulated adrenocorticotropin secretion from AtT-20 cells. Neuroendocrino$\log y$ 75: 339-346.

60. Strowski, M.Z., M. Kohler, H.Y. Chen, et al. 2003. Somatostatin receptor subtype 5 regulates insulin secretion and glucose homeostasis. Mol. Endocrinol. 17: 93-106. 
61. Strowski, M.Z., R.M. Parmar, A.D. Blake \& J.M. Schaeffer. 2000. Somatostatin inhibits insulin and glucagon secretion via two receptors subtypes: an in vitro study of pancreatic islets from somatostatin receptor 2 knockout mice. Endocrinology 141: 111117.

62. Zatelli, M.C., F. Tagliati, D. Piccin, et al. 2002. Somatostatin receptor subtype 1-selective activation reduces cell growth and calcitonin secretion in a human medullary thyroid carcinoma cell line. Biochem. Biophys. Res. Commun. 297: 828-834.

63. Holst, N., M.B. Jacobsen, E. Haug, et al. 1995. Somatostatin in physiological concentrations inhibits basal and enhances luteinizing hormone-stimulated progesterone release from human granulosa-luteal cells. Hum. Reprod. 10: $1363-1366$.

64. Ribeiro, L., F. Martel \& I. Azevedo. 2006. The release of 3H-1-methyl-4-phenylpyridinium from bovine adrenal chromaffin cells is modulated by somatostatin. Regul. Pept. 137: 107-113.
65. Laquerriere, A., P. Leroux, B.J. Gonzalez, et al. 1989. Distribution of somatostatin receptors in the brain of the frog Rana ridibunda: correlation with the localization of somatostatin-containing neurons. J. Comp. Neurol. 280: 451-467.

66. de Lecea, L. 2008. Cortistatin-functions in the central nervous system. Mol. Cell Endocrinol. 286: 88-95.

67. van Hagen, P.M., V.A. Dalm, F. Staal \& L.J. Hofland. 2008. The role of cortistatin in the human immune system. Mol. Cell Endocrinol. 286: 141-147.

68. Dalm, V.A., P.M. van Hagen, P.M. van Koetsveld, et al. 2003. Expression of somatostatin, cortistatin, and somatostatin receptors in human monocytes, macrophages, and dendritic cells. Am. J. Physiol. Endocrinol. Metab. 285: E344-E353.

69. Dalm, V.A., P.M. van Hagen, P.M. van Koetsveld, et al. 2003. Cortistatin rather than somatostatin as a potential endogenous ligand for somatostatin receptors in the human immune system. J. Clin. Endocrinol. Metab. 88: 270-276. 